\title{
Animal Research as a Guide to Regulation and Prevention of Solvent Abuse
}

\author{
Ronald W. Wood
}

\section{Issues of Solvent Dependency}

Inhalant abuse is arguably the most toxic of all substance abuse practices. Consequently, as discussed by several conference participants, biomedical research has focused on the adverse consequences of this form of substance abuse, particularly for the nervous and other organ systems. Such work is of interest not only because of its relevance to inhalant abuse, but also because it contributes to understanding occupational and environmental health problems, and to a basic understanding of the nervous system and its pathophysiology.

Identification of the sequelae of inhalant abuse guides one only in the prevention and treatment of organ toxicity; it adds little guidance to prevent the substance abuse practice itself. If society can devise strategies for preventing inhalant abuse, by definition this will prevent not only solvent-induced organ system toxicity, but also the displacement of socially productive activities. Youths sniffing glue are not learning skills or earning money, but are producing behavior impairment that is incompatible with productive activity and social and intellectual development. 
To devise prevention strategies requires us to address the basic issues of abuse potential and abuse liability. Abuse potential is that portion of a chemical's intrinsic pharmacologic activity, without which there would be no self-administration. Drugs vary in their ability to support self-administration - cocaine and haloperidol being on opposite ends of this spectrum. The Controlled Substances Act embodies this relationship between chemical structure and biological activity in its scheduling process. Abuse liability encompasses both the pharmacological and extrapharmacologic determinants of the substance abuse practice; the availability of the substance, its pattern of distribution and marketing, and social milieus that foster patterns of substance abuse.

Most inhalant products have useful functions in the home and workplace. Although our society may be able to accomplish a reduction in the abuse of cocaine by interdiction, we are no more likely to remove from modern life the volatile chemicals subject to abuse than to give up our dependence on the motor vehicle. We cannot ban gasoline in order to prevent its abuse. However, that does not imply that inhalants are beyond regulatory interventions that might reduce both the incidence of inhalant abuse and its toxic sequelae.

One might hope that the more toxic materials would not be marketed in consumer products and that consumer product formulation might be guided by the intent to reduce abuse potential. Nonetheless, we still find neurotoxicants like hexane in some consumer products. "Poppers," butyl nitrite products, were sold in this country from 1971 until 1988 as room odorizers even though they were subject to abuse and smelled like dirty sweat socks (e.g. "Locker Room, Aroma of Men") and were toxic (Wood 1988). Despite many deaths associated with the deliberate inhalation of chlorofluorocarbon propellants, only the threat of stratospheric ozone depletion resulted in the removal of chlorofluorocarbon propellants from most commercial products. Thus, reduction of abuse potential and toxic sequelae through regulation of commercial products has not been foremost on the agenda of the Federal Government. The difficulties in implementing these types of regulations are apparent in the public records and hearings associated with regulation of the volatile nitrites. Eventually, legislation removed alkyl nitrites from the market place. Unfortunately, these products have been replaced with other "designer nitrites" that apparently fall outside the legislative definition. It might have been easier to control volatile nitrites if the Consumer Product Safety Commission had the discretion to weigh the benefits of the product 
against its abuse liability and risk of bodily injury, and the authority to impose measures ranging from labeling and packaging requirements to an outright ban of selected product formulations.

The role of scientific research is to improve our basic understanding of the phenomena and its determinants, so that society may be able to predict and control the substance abuse practice and its consequences. Although research agendas are readily drawn, the institutional contexts in which such research programs can be conducted remain limited. This is a generic problem in neurobehavioral toxicity evaluation, and was discussed in a recent Office of Technology Assessment report on neurotoxicity (U.S. OTA 1990).

There are few academic environments that consider studies of commercial product formulations to be an appropriate research activity. An academician would not study a proprietary volatile polymerizing agent used in the fiberglass industry in order to determine whether or not it is neurotoxic or has abuse potential. However, if workers have experienced neurotoxic injury by such a material, (e.g. LUCEL7, trimethyltin, carbon disulfide, methylbutyl ketone), then a study of the compound might lead to a new understanding of the structure and function of the nervous system. One should not expect very much product safety evaluation or toxicity screening to be conducted in the university context.

Fundamental research can be conducted in universities to further our understanding of (a) why inhalants are subject to abuse; (b) the nature of their acute and chronic effects; (c) what other drugs of abuse they resemble; (d) the underlying mechanisms of action; and (e) whether abuse potential and toxicity can be predicted in advance of distribution, and with what techniques.

Private research institutes and contractors can explore problems of concern to NIDA, and Pryor's research program is an example of how the contracting mechanism can be used productively to focus on questions that would otherwise not be addressed in academic or industrial contexts. In addition, the contracting mechanism should be used to support projects that are sufficiently challenging or expensive that they will not be undertaken under any other circumstances. Such a project is outlined below in the context of the sequelae of inhalant abuse.

Finally, the corporate and regulatory sectors have a responsibility to address these issues as well. Although the Consumer Product Safety Commission and 
the Food and Drug Administration have been able to regulate inhalants when specific products have led to death (Federal Register Vol. 38, p. 10956, 1973), these two agencies apparently have limited ability to regulate commercially available solvents based on inhalant abuse properties. This is principally because the problem of inhalant abuse has not been interpreted to be within their jurisdiction or mandate. Perhaps this will change if Congress continues to express concern about this problem as it did in the Anti-Drug Abuse Acts of 1986 and 1988. The primary concern of these agencies has been on adequately labeling and packaging products.

Comprehensive premarket toxicity evaluation of commercial chemicals currently falls within the purview of the Environmental Protection Agency (EPA) under the Toxic Substances Control Act (TSCA). The constrained activities of all of these authorities were discussed in detail in a recent U.S. OTA report (1990). On July 18, 1981, EPA solicited comment on the need for testing and appropriate methods for evaluating the abuse potential of an industrial chemical (Federal Register Vol. 45, pp. 48538-48539, 1980). Later in 1981, EPA prepared a test standard for evaluating the abuse potential of inhaled substances under the Toxic Substances Control Act. However, as of now, little useful information has been collected for guiding consumer product formulation or for setting occupational exposure limits for this purpose.

In spite of the magnitude of the challenge to society to cope with this largely ignored substance abuse problem, the research and testing needs are clear. The National Research Council's report on toxicity testing (1984) made it clear that society is not in a position to perform even a minimal toxicity evaluation of 90 percent of the 50,000-plus chemicals in commerce. Among the areas to be evaluated, neurotoxicity was among those of highest priority. Most of the chemicals that are subject to abuse by inhalation fall within the class of chemicals for which occupational exposure limit values have been recommended by the American Conference of Governmental Industrial Hygienists or set by the Occupational Safety and Health Administration. For approximately 30 percent of these chemicals, the recommended exposure limits cite the nervous system as the basis for the recommended exposure limit values. Thus, the adverse effects of volatile chemicals on humans remains one of the principal sources of information used to prevent subsequent injuries, despite the ready availability of techniques to screen for adverse effects using laboratory animals. Frequently, studies in laboratory animals follow the detection of adverse effects in humans, rather than vice 
versa. In this respect, it seems that solvent abusers, who push the dose to extraordinary levels, serve as a special sentinel population for workers and consumers exposed to such chemicals.

\section{Approaches to Addressing the Problem}

Solvent encephalopathy. No large-scale evaluation of the neurotoxicity of organic solvents has been undertaken despite several important prompts, including clear-cut injuries to the nervous system of inhalant abusers, calls for more work by a consensus conference on solvent neurotoxicity (Cranmer and Golberg 1986), and a report of the neurotoxicity of automotive emissions and fuel constituents (Wood 1988b) expressing the need for further solvent neurotoxicity evaluation, the recognition of a psycho-organic syndrome by some European authorities, and the magnitude in the exposed population. Also, most laboratory studies evaluating chronic solvent neurotoxicity have not conformed to the testing guidelines promulgated by EPA and have not employed the appropriate techniques of modern neuroscience to detect and quantify the behavioral and neurological consequences of solvent exposure.

Although appropriate first-tier evaluation of solvent neurotoxicity with rodents would serve to steer the selection of solvent classes for more detailed evaluation, primates are often the most appropriate subjects for detailed study. A series of chronic studies should be considered. These could be conducted in two phases. The first phase would identity the hazards by using concentrations and durations of exposure that are maximally tolerated; then a series of chronic studies using multiple concentrations would provide guidance on the magnitude of the risk. Primates have been recommended for such studies (Cranmer et al. 1986). Studies should include magnetic resonance imaging studies, brain stem auditory evoked responses, evaluation of simple neurological function and conditioned behaviors, and post-mortem quantitative morphometry. The second phase should focus on the sensitive endpoints demonstrated in the first studies, as well on complex conditioned performances for the assessment of "cognitive" impairments and sensory dysfunction.

Abuse potential evaluation. Techniques exist for the evaluation of the abuse potential of inhaled materials (Yanagita et al. 1970; Wood et al. 1977; Wood 1978 1979b; Grubman and Woods 1982). By permitting animals to self-administer solvents one can identify compounds subject to abuse by inhalation. 
These studies also identify the range of concentrations that are effective and can permit the estimation of relative potency, a matter of particular importance in the context of incidental exposures leading to the discovery of intoxicating effects. Although simple self-administration experiments do identify the existence of the hazard, they do not permit the evaluation of relative reinforcing efficacy (i.e., relative risk) from simple rates of response because of the interactions of direct effects and duration of action of the agents. Progressive ratio or choice experiments, where animals are permitted to choose between different concentrations and different agents, are necessary to evaluate relative efficacy. These are slow and labor intensive experiments that are of considerable interest and importance.

Characterizing direct effects with schedule-controlled behavior and other techniques. Techniques used for the characterization of the acute effects of psychoactive drugs can be used to further our understanding of the nature of the effects of inhalants. This strategy relies on using experimental protocols that have been well characterized with particular drugs of abuse, and evaluating the effects of inhalants in a similar manner to develop a profile of action. Using these techniques, some aromatic hydrocarbons have been demonstrated to be anticonvulsants (Wood et al. 1984) or anxiolytics (Wood et al. 1984; Geller et al. 1983), while others produce barbiturate like increases in the frequency of conditioned and unconditioned behavior (Wood and Colotla 1990) and have stimulus properties that resemble barbiturates and anxiolytics (Rees et al. $1987 a, b, c)$.

Drug discrimination studies have proved to be rapid techniques for characterizing unknowns against reference compounds, and broad surveys of solvent classes should be encouraged in this area, with an eye to detecting different patterns of activity. Drug discrimination experiments do not directly address abuse potential, but address the extent of shared stimulus properties with such agents. Tolerance is a hallmark of most drugs with abuse potential. Schedule-controlled operant behavior is appropriate for studying tolerance and its determinants in the context of inhalants (Rees et al. 1989).

Conditioned stimulus effects related to persistence of substance abuse disorders and relapse. Stimuli associated with drug administration or within the context of drug administration can exert powerful control over behavior, both in increasing its strength, exerting powerful control over tolerance development, exposing individuals to exaggerated risks associated with administration in 
unfamiliar environments, and in inducing craving and promoting relapse. Furthermore, the drugs themselves may exert direct effects on the process by which conditioned stimuli become effective or exert their control, e.g., effects on stimulus control or effects on conditioned reinforcing properties.

Irritancy evaluation. Physiological (Kane et al. 1980, Nielsen and Alarie 1982) and behavioral techniques (Wood 1979a; Wood 1981) are available to characterize the irritant potency of inhalants. The initial irritancy of materials may correlate well with their abuse potential (Bowman 1977). Several studies have been performed for related solvents, but major classes have not been examined. Irritancy increases with lipophilicity within a family of related solvents.

Structure-activity determinations. The relationship between an inhalant's structure, associated physicochemical properties, and its pattern of neurobehavioral activities remains poorly known, despite the passage of a century since the promulgation of the Meyer-Overton hypothesis (Overton 1901; Seeman 1972). Systematic research activity of this nature would be of great benefit because it enables the prediction of relative potency and the identification of unusual activity by a solvent that merits more detailed evaluation. By its sensitive nature, such work usually must rely on simple assay systems; nonetheless, work of this nature can also make a significant contribution to occupational and environmental health. Pharmacokinetic determinations have been quite limited in this context. Attempts should be made to determine the nature of the disturbances of neuronal and synaptic function associated with solvent exposure.

Complex performances predictive of cognitive, sensory, and intellectual impairment. Techniques suitable for the detection of gross neurobehavioral toxicity may not detect more subtle impairments produced with chronic exposure. Therefore, research efforts need to be directed at developing procedures that can characterize such impairments in detail, as well as techniques that can detect their occurrence relatively inexpensively in rodents.

Adverse effects on neurobiological development. The fetal alcohol syndrome is now a recognized entity of great concern. There have been several clinical anecdotes suggesting the existence of a fetal solvent syndrome. This deserves further examination to determine if such effects are related to membrane disturbances during development or are attributable to specific compounds or metabolites. 
Tolerance, physical dependence, and withdrawal phenomena. The nature of repeated exposure effects, the extent of tolerance, and its dependence on environmental variables has received only limited attention (e.g., Rees et al. 1989). Withdrawal from solvents has produced only limited evidence of a withdrawal syndrome, and this may be attributable to the duration of action of solvents. Ethanol is illustrative of the difficulties associated with producing sustained nervous system concentrations of inhaled agents. Some solvents may accumulate with repeated exposure (Rees et al. 1989) and may clear slowly enough so that withdrawal signs are not expressed. Work with benzodiazepines has indicated that significant dependence potential exists with compounds that mask their own withdrawal (Lukas and Griffiths 1982). Comparable phenomena are likely to occur with solvents.

Human studies of direct solvent effects. Cross-species extrapolation is of principal concern for many toxicity evaluations. By its very nature, the study of potentially neurotoxic chemicals in humans has been quite limited, and has been restricted to the study of smaller marginal effects. Studies of higher level exposures characteristic of human solvent abuse have not been undertaken, but would be of great interest, just as is the study of relatively high doses of cocaine in human subjects. Attempts might be made to gather more information at high and low levels of exposure to relatively innocuous solvents in human subjects.

Mechanistic studies. We have little information about the biochemical and neuropharmacologic consequences of inhalant abuse. In the case of demonstrable ototoxicity, we have little insight into the mechanism of this injury. Is the injury due to the parent compound or a metabolite? Is the hearing loss attributable to an acidotic change in the inner ear overcoming the buffering capacity of the endolymph? Mechanistic studies become of great importance once the hazards associated with a particular solvent or solvent mixture have been identified.

\section{Concluding Remark}

Substance abuse practices are dependent on a biological substrate of susceptibility to reinforcement by chemicals, a pharmacologic "original sin." Focusing on populations that are at risk is of importance because it can identify the familial, social, and cultural factors that predispose to substance abuse. However, to characterize inhalant abuse as "perverted use" appears to 
imply a moral or personality defect in the user. Despite the fact that the population at greatest risk is below the age of consent, such stigmatization of the user works against the effectiveness of therapeutic interventions intended to promote the adoption of behaviors incompatible with substance abuse and the reintegration of the user as a useful member of society. Products with intrinsic toxicities are regulated to minimize injuries, and that regulatory authority should be extended to minimize inhalant abuse and its toxic sequelae.

\section{References}

Bowman, R.E. Preclinical behavioral toxicology of inhalant solvents. In: Sharp, C.W., and Brehm, M.L., eds. Review of Inhalants: Euphoria to Dysfunction. NIDA Research Monograph 15. Rockville, MD: National Instutute on Drug Abuse, 1977.

Cranmer, J.; Golberg, L.; Brown, T.D.; Gibson, J.E.; and Reiter, L.W. Neurobehavioral effects of solvents: Proceedings of an international conference. Neurotoxicology 7(4):1-95, 1986.

Geller, I.; Hartmann, R.J.; Mendez, V.; and Gause, E.M. Toluene inhalation and anxiolytic activity: Possible synergism with diazepam. Pharmacol Biochem Behav 19:899-903, 1983.

Grubman J., and Woods, J.H. Schedule-controlled behavior maintained by nitrous oxide delivery in the rhesus monkey. In: Learning and Memory Drugs as Reinforcer. Amsterdam: Excerpta Medica, 1982. pp. 259-274.

Kane, L.E.; Dombroske, R.; and Alarie, Y. Evaluation of sensory irritation from some common industrial solvents. Amer Ind Hyg Assoc J 41:451$455,1980$.

Lukas, S., and Griffiths, R. Precipitated withdrawal by a benzodiazepine receptor antagonist (Ro 15-1788) after 7 days of diazepam. Science 217:1161-1163, 1982.

National Research Council. Toxicity Testing. Strategies to Determine Needs and Priorities. Washington, DC: National Academy Press, 1984. 
Nielsen, G.D., and Alarie, Y. Sensory irritation, pulmonary irritation, and respiratory stimulation by airborne benzene and alkylbenzenes: Prediction of safe industrial exposure levels and correlation with their thermodynamic properties. Toxicol Appl Pharmacol 65:459-477, 1982.

Overton, E. Studien uber die Norkose Zugleich ein Beitrag zur Allegemeinen Pharmakologie. Jena, Verlag von Gustav Fisher, 1901.

Rees, D.C.; Knisely, J.S.; Balster, R.L.; Jordan, S.; and Breen, T.J. Pentobarbital-like discriminative stimulus properties of halothane, 1,1,1trichloroethane, isoamyl nitrite, flurothyl and oxazepam in mice. $J$ Pharmacol Exp Ther 241:507-515, 1987a.

Rees, D.C.; Knisely, J.S.; Breen, T.J.; and Balster, R.L. Toluene, halothane, 1,1,1-trichloroethane, and oxazepam produce ethanol-like discriminative stimulus effects in mice. J Pharmacol Exp Ther 243:931-937, 1987b.

Rees, D.C.; Knisely, J.S.; Jordan, S.; and Balster, R.L. Discriminative stimulus properties of toluene in the mouse. Toxicol Appl Pharmacol 88:97-104, $1987 c$.

Rees, D.C.; Wood, R.W.; and Laties, V.G. Evidence of tolerance following repeated exposure to toluene in the rat. Pharmacol Biochem Behav 32:283-291, 1989.

Seeman, P. The membrane actions of anesthetics and tranquilizers. Pharmacol Rev 24:583-655, 1972.

U.S. Congress. Office of Technology Assessment. Neurotoxicity. Identifying and Controlling Poisons of the Nervous System. OTA-BA-436. Washington, DC: U.S. Govt. Print. Off., 1990. pp. 92-94.

U.S. Government. Air Contaminants; Final Rule. Federal Register 54:(12)2332-2983, 1989.

Wood, R.W. The stimulus properties of inhaled substances. Environ Health Perspect 26:69-76, 1978.

Wood, R.W. Behavioral evaluation of sensory irritation evoked by ammonia. Toxicol Appl Pharmacol 50:157-162, 1979a. 
Wood, R.W. Reinforcing properties of inhaled substances. Neurobehavioral Toxicology (1 Supp. 1):67-72. Errata: 2, 63, $1979 b$.

Wood, R.W. Determinants of irritant termination behavior. Toxicol Appl Pharmacol 61:260-268, 1981.

Wood, R.W. The acute toxicity of nitrite inhalants. In: Haverkos, H., ed. Extent of Use and Health Hazards of Nitrite Inhalants. National Institute on Drug Abuse Monograph 83. Rockville, MD: National Institute on Drug Abuse, 1988a. pp. 28-38.

Wood, R.W. Identifying neurobehavioral effects of automotive emissions and fuel components. In: Kennedy, D., and Bates, R., eds. Air Pollution, the Automobile, and Public Health. Washington, DC: National Academy Press, 1988b. pp. 631-657.

Wood, R.W.; Coleman, J.; Schuler, R.; and Cox, C. Anticonvulsant and antipunishment effects of toluene. J Pharmacol Exp Ther 230:407-412, 1984.

Wood, R.W., and Colotla, V.A. Biphasic changes in mouse motor activity during toluene exposure. Fund Appl Toxicol 14:6-14, 1990.

Wood, R.W.; Grubman, J.; and Weiss, B. Nitrous oxide self-administration by the squirrel monkey. J Pharmacol Exper Ther 202:491-499, 1977.

Wood, R.W., and Weiss, B. Volatile anesthetic self-administration by the squirrel monkey. In: Sharp, C.W., and Carroll, L.T., eds. Voluntary Inhalation of Industrial Solvents. Rockville, MD: National Institute on Drug Abuse, 1978. pp. 355-362.

Yanagita, T.; Takahashi, S.; Ishida, K.; and Funamoto, H. Voluntary inhalation of volatile anesthetics and organic solvents by monkeys. Jpn J Clin Pharm 1:13-16, 1970. 


\section{Acknowledgment}

Supported by K02-DA00117 and RO1-DA04438 from the National Institute on Drug Abuse.

\section{Author}

Ronald W. Wood, Ph.D.

Research Associate Professor

of Environmental Medicine

New York University Medical Center

550 First Avenue

New York, NY 10016 


\section{National Institute on Drug Abuse}

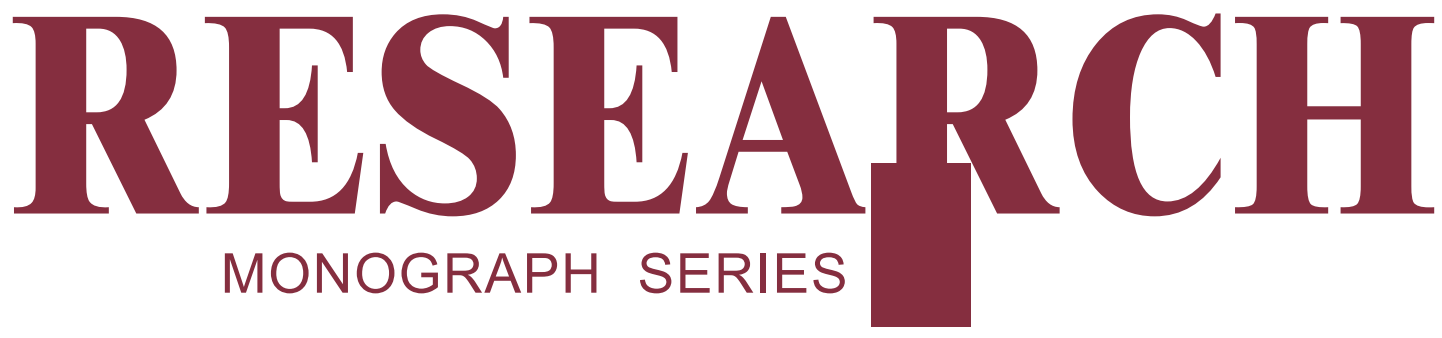

\section{Inhalant Abuse: A}

\section{Volatile Research}

\section{Agenda}
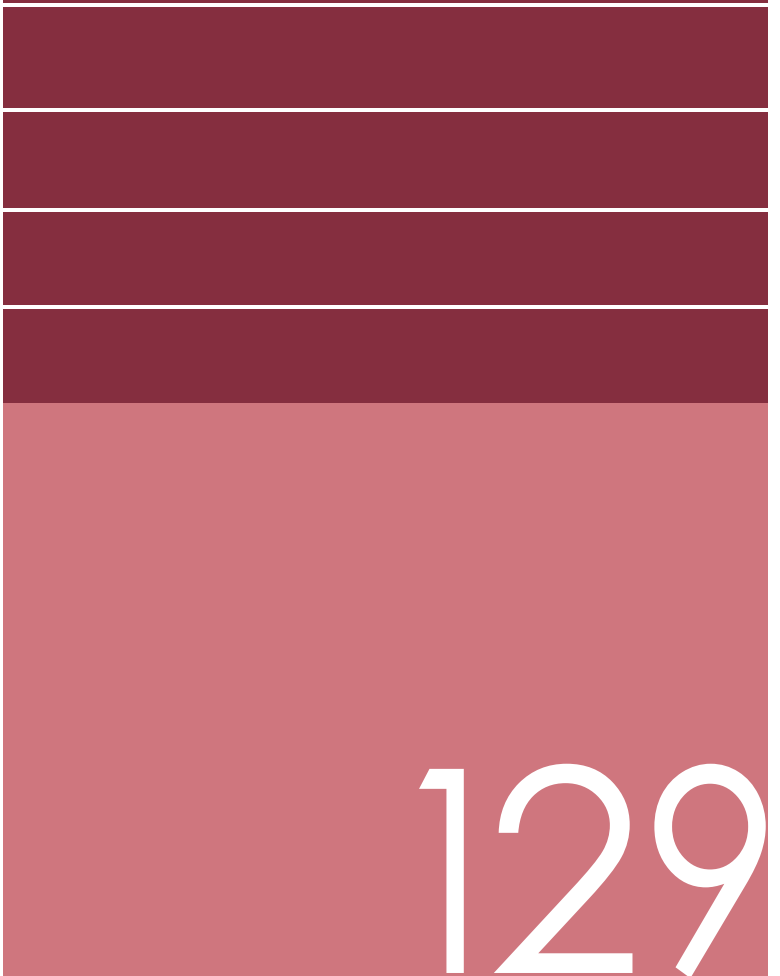


\section{Inhalant Abuse: A Volatile Research Agenda}

Editors:

Charles Wm. Sharp, Ph.D.

Fred Beauvais, Ph.D.

Richard Spence, Ph.D.

NIDA Research Monograph 129

1992

U.S. DEPARTMENT OF HEALTH AND HUMAN SERVICES

Public Health Service

National Institutes of Health

National Institute on Drug Abuse

5600 Fishers Lane

Rockville, MD 20857 


\section{ACKNOWLEDGMENT}

This monograph is based on the papers from a technical review on "Inhalant Abuse" held in 1989. The review meeting was sponsored by the National Institute on Drug Abuse and the Texas Commission on Alcohol and Drug Abuse.

\section{COPYRIGHT STATUS}

The National Institute on Drug Abuse has obtained permission from the copyright holders to reproduce certain previously published material as noted in the text. Further reproduction of this copyrighted material is permitted only as part of a reprinting of the entire publication or chapter. For any other use, the copyright holder's permission is required. All other material in this volume except quoted passages from copyrighted sources is in the public domain and may be used or reproduced without permission from the Institute or the authors. Citation of the source is appreciated.

Opinions expressed in this volume are those of the authors and do not necessarily reflect the opinions or official policy of the National Institute on Drug Abuse or any other part of the Department of Health and Human Services.

The U.S. Government does not endorse or favor any specific commercial product or company. Trade, proprietary, or company names appearing in this publication are used only because they are considered essential in the context of the studies reported herein.

National Institute of Drug Abuse

NIH Publication No. 93-3475

Printed 1992

NIDA Research Monographs are indexed in the Index Medicus. They are selectively included in the coverage of American Statistics Index, BioSciences Information Service, Chemical Abstracts, Current Contents, Psychological Abstracts, and Psychopharmacology Abstracts. 